\title{
A Light Microscopic Radioautographic Study on Protein Synthesis in Pulmonary Cells of Aging Mice
}

\author{
Lin Sun, Fulu Gao and Tetsuji Nagata \\ Department of Anatomy and Cell Biology, Shinshu University School of Medicine, 3-1-1 Asahi, Matsumoto 390
}

Received for publication August 22, 1997 and in revised form December 1, 1997

\begin{abstract}
In the present study we first investigated the changes in protein synthesis of respective cell types of mouse pulmonary alveoli from 16 days of fetal life to senility (postnatal 22 months) by using ${ }^{3} \mathrm{H}$-leucine light microscopic radioautography. The results revealed that the protein syntheses in type I epithelial cells, type II epithelial cells, interstitial cells and endothelial cells in the mouse lung changed due to aging. The protein synthesis of type I epithelial cells was the highest on postnatal day 1 , increased

creased gradually to $\mathbf{2 2}$ months after birth with aging. The protein syntheses of type II epithelial cells, interstitial cells and endothelial cells reached the highest level on fetal day 16, declined progressively with age, and increased again at postnatal 1 week, and then decreased gradually from 2 weeks to senility. Our results suggest that the decreases in protein synthesis are correlated with the decremental changes in DNA and RNA synthesis in the lung with aging.
\end{abstract} again at 1 week after birth, and then de-

Key words: Protein synthesis, Aging, Lung, Radioautography, Mice

\section{Introduction}

Protein synthesis is crucial for the survival of a living system. It is one of the biochemical processes that has been shown to change with increasing age in various tissues and organs, such as the muscle [19], heart [37], spleen [37], small and large intestines [15], liver [18, 20-23], pancreas [31-34], kidney [13, 37], testis [8-11], uterus [44], retina [42] and brain [5, 24].

Although the changes for protein synthesis and turnover in the lungs of aging animals have been investigated by several authors $[12,14,26,37]$, detailed studies on protein synthesis of respective pulmonary cell types from the fetus through to senescence have not been carried out until now. We have reported recently that nucleic acid DNA and RNA synthesis in pulmonary cells underwent agedependent changes at different ages in mice [38-41]. Therefore, in this study, we investigated the changes for protein synthesis in the respective pulmonary cell types (including type I epithelial cells, type II epithelial cells, interstitial cells and endothelial cells) of aging mice from embryonic stages to adult and senescent stages by light microscopic radioautography.

Correspondence to: Professor Tetsuji Nagata, Department of Anatomy and Cell Biology, Shinshu University School of Medicine, 3-1-1 Asahi, Matsumoto 390, Japan.

\section{Materials and Methods}

\section{Animals and tissues}

Experiments were performed on 30 male ddY strain mice divided in ten groups: fetal day 16 and 18 (vaginal plug $=$ day 0 ), postnatal day 1 and 3,1 and 2 weeks, 1,6 , 12 and 22 months (at birth = day 1 ), each consisting of 3 litter individuals. The mice were bred in our laboratory, fed on normal mice diet (Clea CE2, Tokyo, Japan) and were given water ad libitum under normal conditions.

\section{Tissue processing}

After the mice were sacrificed by decapitation at a given time (1:00 p.m.), the lungs were immediately removed aseptically and cut into small tissue blocks $(1 \times$ $1 \times 1 \mathrm{~mm}$ ) in Hanks' solution (Nissui, Tokyo, Japan). The tissue blocks were incubated in Eagle's MEM (Nissui, Tokyo, Japan) containing 10\% fetal bovine serum (GIB$\mathrm{CO}$, Grand Island, USA) and ${ }^{3} \mathrm{H}$-leucine (NEN, specific activity $185 \mathrm{MBq} / \mathrm{mM}$, at a concentration of $3.7 \mathrm{MBq} / \mathrm{ml}$ ) in a $\mathrm{CO}_{2}$ incubator (Tabai, Tokyo, Japan) with $5 \% \mathrm{CO}_{2}$ in air at $37^{\circ} \mathrm{C}$ in vitro for $1 \mathrm{hr}$. After three washes with Hanks' solution, the tissue blocks were prefixed in $2.5 \%$ glutaraldehyde in phosphate buffer $(0.1 \mathrm{M}, \mathrm{pH} 7.4)$ at $4^{\circ} \mathrm{C}$ for $1 \mathrm{hr}$, and postfixed with $1 \%$ osmium tetroxide in the same buffer at $4^{\circ} \mathrm{C}$ for $1 \mathrm{hr}$. They were dehydrated with a graded series of ethanol and acetone, and then embedded 
in Epok 812 (Oken, Tokyo, Japan).

\section{Light microscopic radioautography (LMRAG)}

The $2 \mu \mathrm{m}$-thick sections were cut with a Porter-Blum MT-2B ultramicrotome (Dupont-Sorvall, Newtown, USA), and were mounted on microscopic glass slides. They were then coated simultaneously with Konica NRM2 radioautographic emulsion (Konica Photo Industry Co., Tokyo, Japan) by mass production procedure using the dipping method by Nagata [28-30]. After exposure in light-proof boxes at $4^{\circ} \mathrm{C}$ for 14 weeks, all the coated slides were developed at once with SDX-1 developer (Konica) in a water bath at $20^{\circ} \mathrm{C}$ for $5 \mathrm{~min}$, and fixed in acid fixer for $10 \mathrm{~min}$, rinsed and stained with $0.05 \%$ toluidine blue simultaneously. Thus, all the slides were processed for radioautography under the same conditions, so that all the specimens could be used for quantitative analysis. The radioautographs were examined and photographed using an Olympus Vanox AHB-LB light microscope.

\section{Quantitative analysis}

In order to elucidate quantitative changes of protein synthesis in the cell bodies and nuclei of respective types of pulmonary cells in the alveolar walls, they were classified into 4 types, type I alveolar epithelial cells (squamous alveolar cells), type II alveolar epithelial cells (great alveolar cells), interstitial cells and endothelial cells and the number of silver grains over the cell bodies and nuclei at each age was counted separately [30]. From each animal at least 300 cells and totally about 1200 pulmonary cells of each age group were counted randomly. The average numbers of the silver grains over the cytoplasm and nuclei in pulmonary cells at each age were calculated, and were presented as mean \pm SD. All the data were analyzed statistically using the Student's t test, and the differences between respective age groups were considered to be significant when the $\mathbf{P}$ value was less than 0.05 .

\section{Results}

\section{Qualitative observations}

The lungs of fetal day 16 animals showed gland-like structure. The alveolar epithelia consisted of undifferentiated cuboidal epithelial cells appearing as type II epithelial cells and no squamous epithelial cells were seen (Fig. 1). Examination of light microscopic radioautograms (LMRAG) showed that a large number of silver grains were found over the cytoplasm and nuclei of the cuboidal epithelial cells, interstitial cells and endothelial cells (Fig. 1). On fetal day 18, the alveolar epithelia were lined exclusively with type II alveolar epithelial cells, while no type I squamous epithelial cell was found. At this stage the number of silver grains over the cytoplasm and nuclei of the type II alveolar epithelial cells, interstitial cells and endothelial cells slightly decreased as compared with fetal day 16 (Fig. 2).

On postnatal day 1 , the lung of a newborn mouse con- sisted of primary saccules, consisting of alveolar epithelial cells which were surrounded by double capillary networks. The alveolar epithelia consisted of both type I and type II alveolar epithelial cells (Fig. 3). On postnatal day 3 , the structure of the lung had further developed (Fig. 4). LMRAG showed that many silver grains were found over the cytoplasm and nuclei of type I epithelial cells, type II epithelial cells, interstitial cells and endothelial cells on postnatal day 1 and 3 . The numbers of silver grains over the cytoplasm and nuclei in 4 types of pulmonary cells were less than those of the embryonic stage (Figs. 3, 4).

At 1 week after birth, the morphology of the lung showed complete alveolar structure with adult-like single capillary system. Examination of LMRAG showed that many silver grains were seen over the cytoplasm and nuclei of type I epithelial cells, type II epithelial cells, interstitial cells and endothelial cells (Fig. 5). A definite increase in the number of silver grains over the cytoplasm and nuclei in 4 types of pulmonary cells was observed as compared with postnatal day 3 .

From postnatal 2 weeks to 6 months, some silver grains were seen over the cytoplasm and nuclei of type I epithelial cells, type II epithelial cells, interstitial cells and endothelial cells. The number of silver grains over the cytoplasm and nuclei diminished gradually with increasing age (Figs. 6-8).

From 12 months to 22 months after birth, the number of silver grains over the cytoplasm and nuclei in type I epithelial cells, type II epithelial cells, interstitial cells and endothelial cells reduced markedly (Figs. 9, 10). At 22 months after birth, only few silver grains were found over the cytoplasm of type I epithelial cells, type II epithelial cells, interstitial cells and endothelial cells (Fig. 10).

\section{Quantitative analysis}

Light microscopic radioautograms at different ages labeled with ${ }^{3} \mathrm{H}$-leucine showed that the numbers of silver grains over the nuclei were less than those of the cell bodies. In addition, the numbers of silver grains were less in the type I epithelial cells and endothelial cells than those in the type II epithelial cells and interstitial cells at the same age groups (Figs. 11-14).

The number of silver grains over the cytoplasm and nuclei in 4 types of pulmonary cells showed the age-dependent change due to aging (Figs. 11-14). As shown in Fig. 11 , the average number of silver grains over the cytoplasm and nuclei of type I epithelial cells reached its maximum on postnatal day 1 , then decreased on postnatal day 3 , reached postnatal peak at 1 week after birth. They fell down progressively from 2 weeks after birth on, dropped to the lowest value at 22 months after birth. As seen in Fig. 12, on fetal day 16, the average number of the silver grains over the cytoplasm and nuclei of cuboidal epithelial cells was maximal. From fetal day 18, the average number of the silver grains over the cytoplasm and nuclei of type II epithelial cells decreased with time, then increased again at 1 week after birth $(P<0.05)$, and declined 


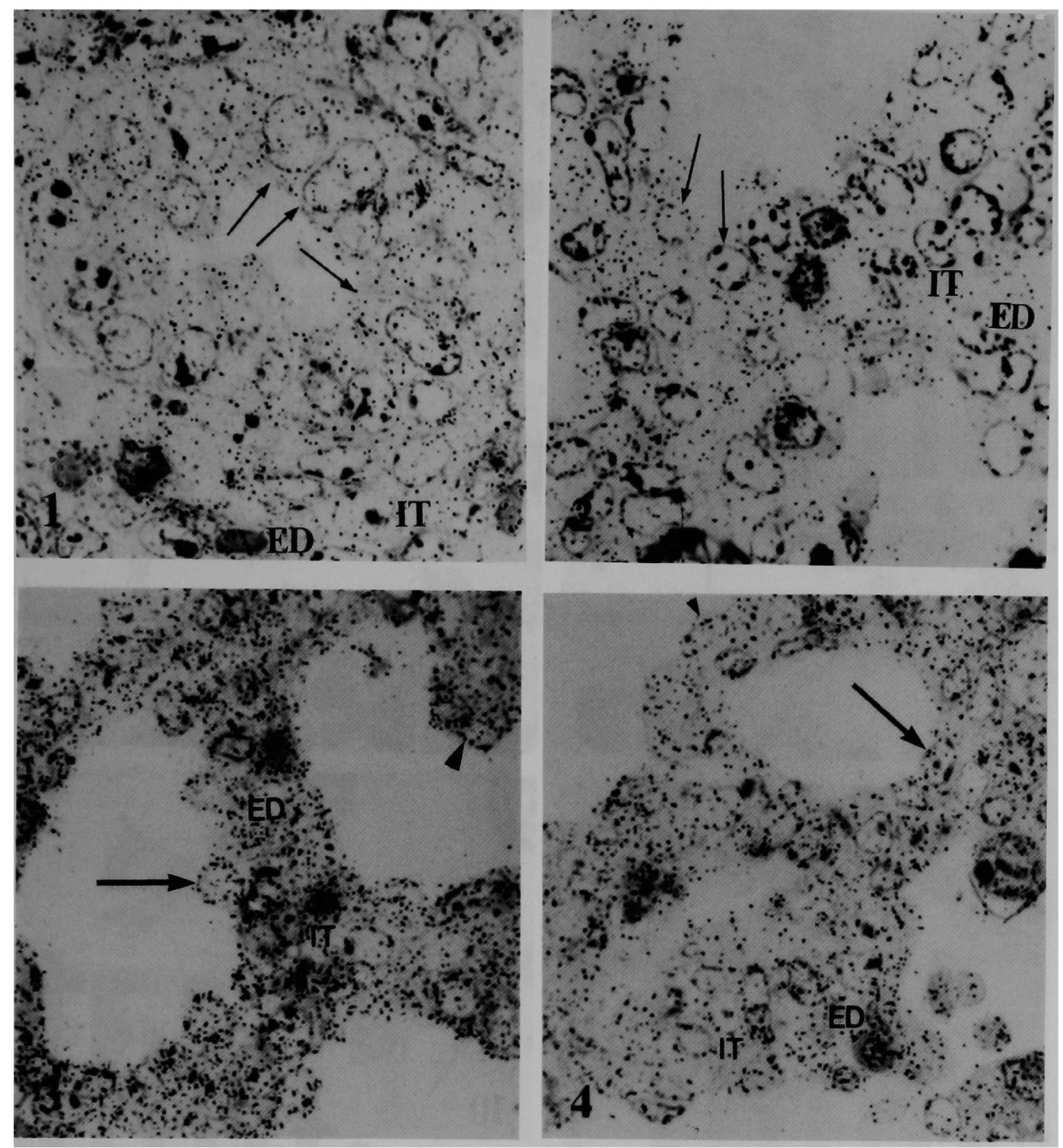

Fig. 1. A light microscopic radioautogram (LMRAG) of the lung from a mouse embryo labeled with ${ }^{3} \mathrm{H}$-leucine on fetal day 16 . A large number of silver grains are observed over the cytoplasm and nuclei of cuboidal epithelial cells (arrows), interstitial cells (IT) and endothelial cells (ED). $\times 1200$.

Fig. 2. LMRAG of the lung in mouse embryo labeled with ${ }^{3} \mathrm{H}$-leucine on fetal day 18 . Numbers of silver grains are found over the cytoplasm and nuclei of type II cuboidal epithelial cells (arrows), interstitial cells (IT) and endothelial cells (ED). $\times 1100$.

Figs. 3, 4. LMRAG of newborn mouse lungs on postnatal day 1 (Fig. 3), and 3 (Fig. 4). After incubation with ${ }^{3} \mathrm{H}-$ leucine, many silver grains are seen on the cytoplasm and nuclei of type I epithelial cells (arrow heads), type II epithelial cells (arrows), interstitial cells (IT) and endothelial cells (ED). $\times 1000$.

gradually from 2 weeks to 22 months after birth. The average number of the silver grains over the cytoplasm and nuclei of interstitial cells reached its maximum on fetal day 16, diminished with aging, increased at 1 week after birth as compared with postnatal day $3(\mathrm{P}<0.05)$, then decreased progressively from 2 weeks to 22 months after birth with aging (Fig. 13). The average number of the silver grains over the cytoplasm and nuclei of endothelial cells reached the maximum on fetal day 16 , fell down from fetal day 18, increased markedly at 1 week after birth
$(\mathrm{P}<0.05)$, then decreased gradually from 2 weeks to 22 months after birth (Fig. 14). Significant differences were mostly found among the different age groups by Student's $t$ test (Figs. 11-14).

\section{Discussion}

The protein synthesis of cells and tissues can be demonstrated by light and electron microscopic radioautography after administration of ${ }^{3} \mathrm{H}$-leucine which 


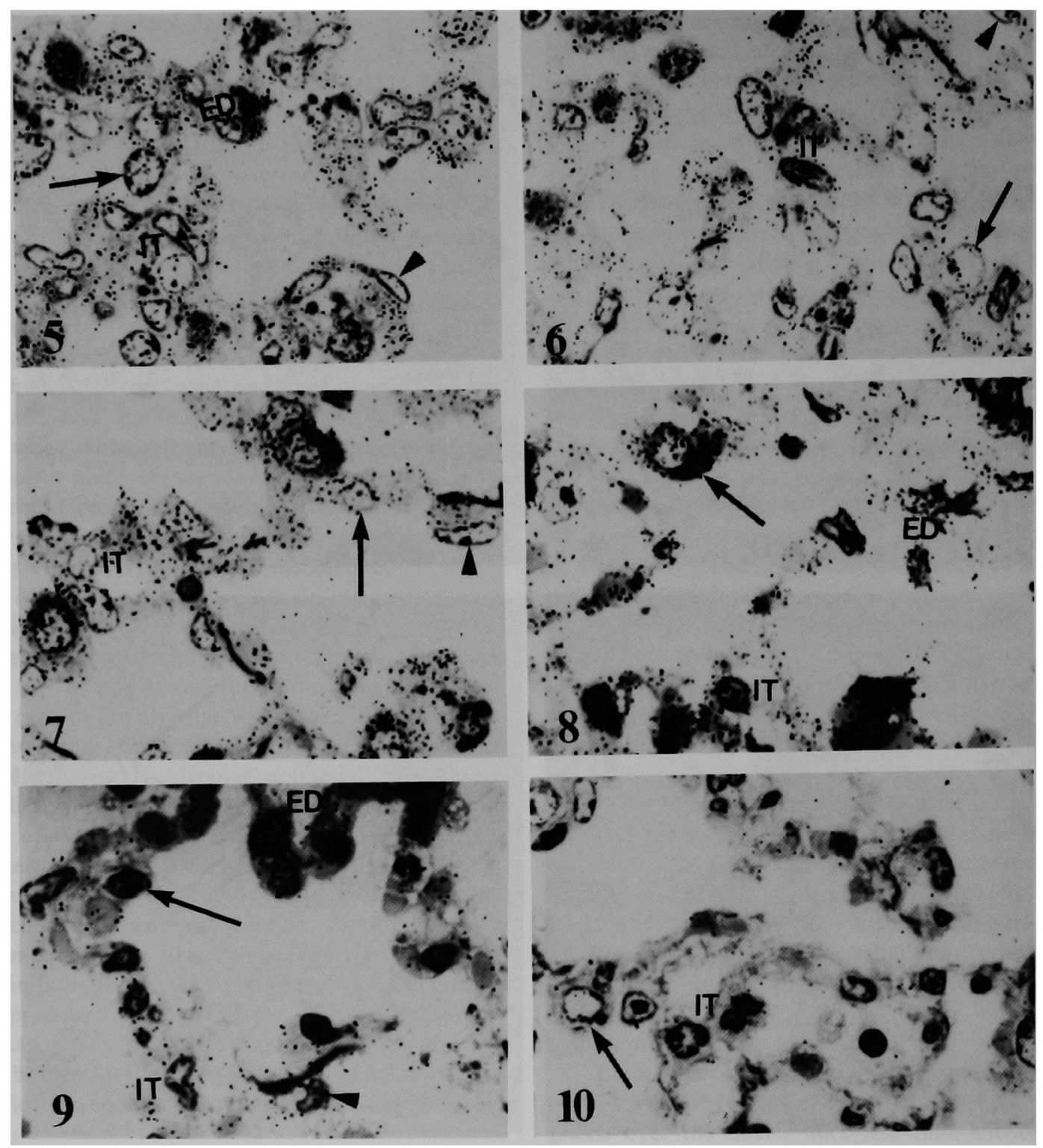

Figs. 5, 6. LMRAG of the lungs in young mice labeled with ${ }^{3} \mathrm{H}$-leucine at postnatal 1 (Fig. 5), and 2 (Fig. 6) weeks. Many silver grains are found on the cytoplasm and nuclei of type I epithelial cells (arrow heads), type II epithelial cells (arrows), interstitial cells (IT) and endothelial cells (ED). $\times 1200$.

Figs. 7, 8. LMRAG of the lungs in adult mice labeled with ${ }^{3} \mathrm{H}$-leucine at postnatal 1 (Fig. 7), and 6 (Fig. 8) months. Some silver grains are observed on the cytoplasm and nuclei of type I epithelial cells (arrow head), type II epithelial cells (arrows), interstitial cells (IT) and endothelial cells (ED). $\times 1200$.

Fig. 9. LMRAG in the senile mouse lung labeled with ${ }^{3} \mathrm{H}$-leucine at postnatal 12 months. Several silver grains are seen on the cytoplasm and nuclei of a type I epithelial cell (arrow head), a type II epithelial cell (arrow), an interstitial cell (IT) and an endothelial cell (ED). $\times 1100$.

Fig. 10. LMRAG in the senile mouse lung labeled with ${ }^{3} \mathrm{H}$-leucine at postnatal 22 months. Only few silver grains are found on the cytoplasm of a type II epithelial cell (arrow) and an interstitial cell (IT). $\times 1100$.

is incorporated into both nuclei demonstrating nucleoprotein synthesis and cell bodies demonstrating cytoplasmic protein synthesis in cell organelles such as endoplasmic reticulum, Golgi apparatus from which they are transferred to cytoplasmic ground substance or secretory granules and finally discharged outside the cells [33].

Our radioautographic results in this study demonstrated the age-dependent change of protein syn- thesis in pulmonary cells from embryonic stage to postnatal senescent stages with aging. The examination of radioautograms revealed that the protein syntheses of 4 types of pulmonary cells reached the highest level at the perinatal stage on fetal day 16 or postnatal day 1 , then decreased gradually with age, increased again at 1 week after birth, then declined progressively at the adult stage from 2 weeks to 22 months after birth. In respective aging 


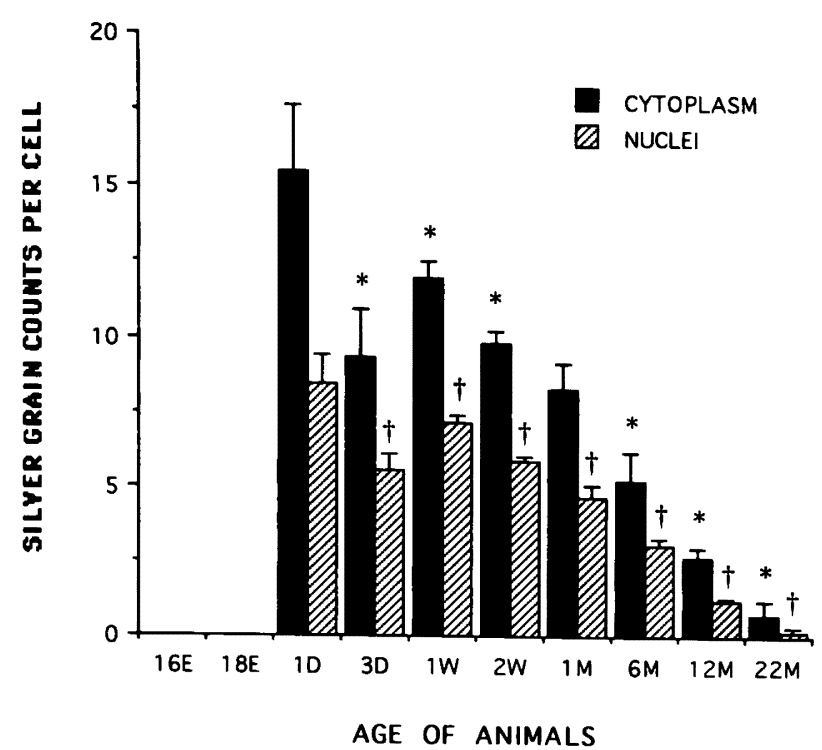

Fig. 11. The changes in silver grain counts of type I epithelial cells in aging mouse lungs labeled with ${ }^{3} \mathrm{H}$-leucine at various age groups. Mean \pm SD. Significantly different from the prior age group on the cytoplasm $(*)$ and nuclei $(\dagger)$ at $P<0.05$ using the Student's $t$-test.

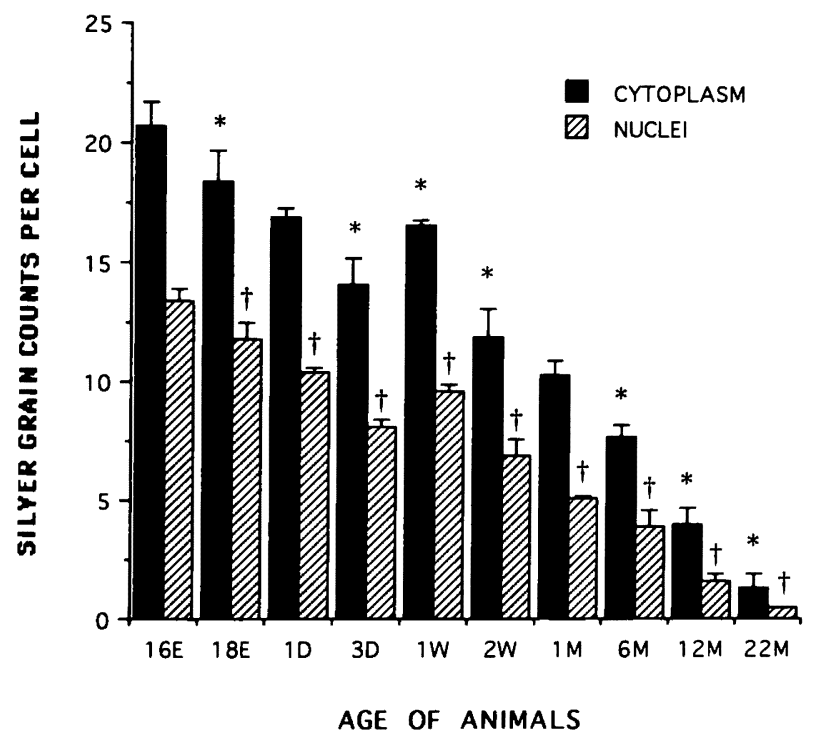

Fig. 13. The changes in silver grain counts of interstitial cells in aging mouse lungs labeled with ${ }^{3} \mathrm{H}$-leucine in different age groups. Mean $\pm S D$. Significantly different from the prior age group on the cytoplasm (*) and nuclei ( $\dagger$ ) at $\mathbf{P}<0.05$ using the Student's $t$-test.

groups, the grain counts in cell bodies were always higher than the nuclei. The result means that the cytoplasmic protein synthesis was more than the nucleoprotein synthesis. On the other hand, when the total grain counts including both nuclear and cytoplasmic protein syntheses,

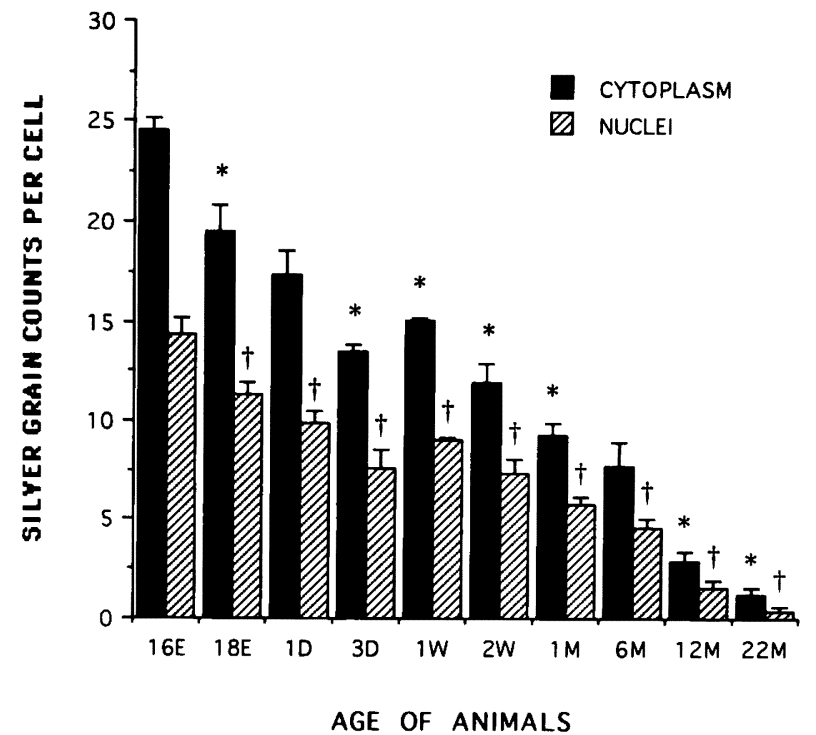

Fig. 12. The changes in silver grain counts of type II epithelial cells (cuboidal epithelial cells on fetal day 16) in aging mouse lungs labeled with ${ }^{3} \mathrm{H}$-leucine. Mean \pm SD. Significantly different from the prior age group on the cytoplasm $\left({ }^{*}\right)$ and nuclei $(\dagger)$ at $P<0.05$ by Student's $t$-test.

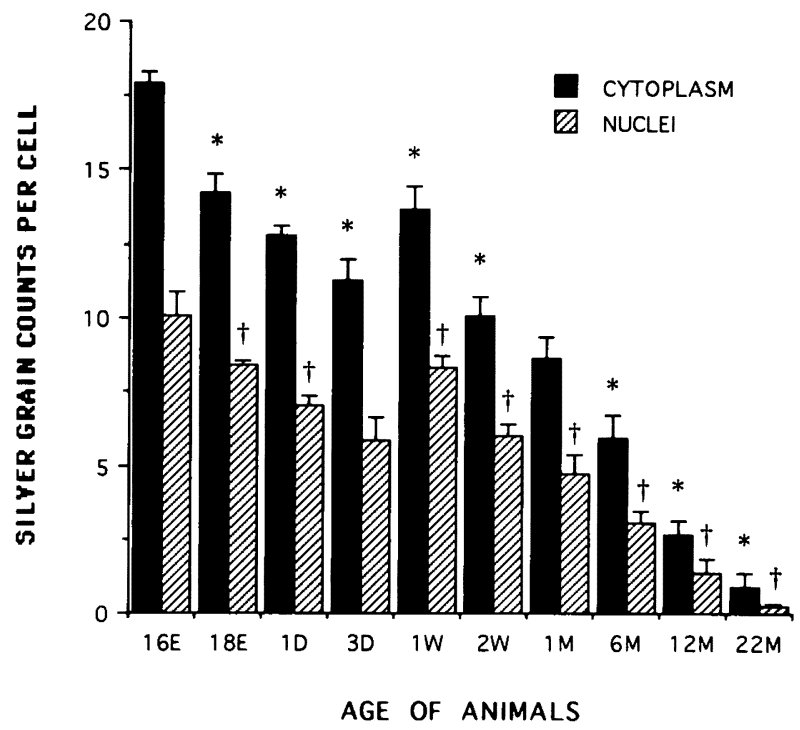

Fig. 14. The changes in silver grain counts of endothelial cells in aging mouse lungs labeled with ${ }^{3} \mathrm{H}$-leucine at various ages. Mean $\pm S D$. Significantly different from the prior age group on the cytoplasm $\left({ }^{*}\right)$ and nuclei $(\dagger)$ at $P<0.05$ by Student's $t$-test. were compared with respective aging groups, the results indicated that the protein syntheses of type II epithelial cells, interstitial cells and endothelial cells reached the highest on fetal day 16 , then decreased from fetal day 18 to postnatal day 3 with aging. The findings are in agreement with our 
previous studies on the age-related changes in the DNA synthesis of pulmonary cells [39-41]. We found that the DNA syntheses of cuboidal epithelial cells, interstitial cells and endothelial cells were at their maxima on fetal day 16. The results in the present study are similar to those examined biochemically in the rat lung, the fractional rate of protein synthesis (the percentage of the protein mass synthesized per day) actually decreased from fetal (93\%) to neonatal life (33\%) [12]. The marked decrease in the fractional rate of protein synthesis corresponded to an agerelated decline in the rate of lung growth. The decline in the protein synthetic rate between fetal life and weaning was more closely associated with a fall in the ribosomal capacity (i.e. RNA/protein) than in the ribosomal activity (i.e. protein synthesis/RNA) within the lung. However, these results did not show the difference among the respective cell types of the lung.

The radioautograms in the present study revealed the difference among the cell types. The protein syntheses of type II epithelial cells and interstitial cells increased again at postnatal 1 week, and those of type I epithelial cells and endothelial cells reached their postnatal peaks at 1 week after birth. These findings are in keeping with our recent studies on the RNA synthesis in the pulmonary cells [38]. We reported that the RNA syntheses in type I epithelial cells, type II epithelial cells, interstitial cells and endothelial cells were at their maxima at 1 week after birth. In addition, the report by Burry [4] that after a slow start, an explosive restructuring of lung parenchyma occurs between postnatal days 4 and 7 also supports our findings.

Our results from this investigation demonstrated that the protein syntheses in type I epithelial cells, type II epithelial cells, interstitial cells and endothelial cells decreased gradually from 2 weeks to 22 months after birth. The molecular mechanisms responsible for decline in protein synthesis of pulmonary cells with age are still poorly understood. This may be due to the following reasons: (1) We found that the DNA syntheses of 4 types of pulmonary cells decreased gradually from postnatal 1 week to 22 months [39-41], and RNA syntheses of 4 types of pulmonary cells diminished gradually from 2 weeks to 22 months after birth [38]. The decrease in the DNA and RNA syntheses could result in a gradual decline in the protein synthesis. (2) The rate of lung growth gradually decreased from weaning to old age in the rat lung [14]. (3) The amount of eukaryotic initiation factor 2 (eIF-2) in the lung fell with increasing age [17]. The results by Kimball et al. [17] suggested that the regulation of elF-2 synthesis during aging may cause the change at the translational rather than the transcriptional level. Overall, it seems likely that the decrease in DNA and RNA synthesis in the lung growth and eIF- 2 content may play important roles in the decremental changes in protein synthesis occurring in the lung with aging. On the other hand, studies on agerelated changes in various components of the protein synthetic machinery were carried out in various tissues and organs. For example, (1) A decrease in the efficiency and accuracy of ribosomes which results in an increase of translational errors and a decrease of accuracy of protein synthesis was reported during aging [35]. (2) The activity of elongation factor $1(\mathrm{EF}-1)$ decreased with age in rat livers and Drosophila, and the drop paralleled the decrease in protein synthesis. A decline in the amount of active EF-2 was found during aging in human fibroblasts in culture [36].

The present results showing a decrease in protein synthesis of pulmonary cells with age are consistent with the previous reports by other investigators [25, 26, 37]. Mays and coworkers found that protein synthesis rates for total proteins in the lung decreased during the first 6 months $[25,26]$. Shahbazian and coworkers also reported that the protein synthesis rate of the lung was higher $(1.6 \%)$ in immature animals than in adult animals (1.0\%) [37]. The decremental changes of protein synthesis with aging were found in many organs and tissues $[1,13,15,16,19,33,34$, 43]. For example, the radioautographic examinations by Nagata [31-34] showed that the protein synthesis in the pancreas increased from prenatal to postnatal day 14 , then decreased from 1 month to 1 year. The protein synthesis of the hepatocytes reached the maximum at postnatal 1 month, then decreased with aging to 24 months [20-23]. In the skeletal muscle, the heart and the skin, protein synthesis rates decreased during the first 6 months [26]. Analysis of in vivo protein synthesis rates revealed a decline of $20 \%$ in cerebral cortex of old rats [7]. On the other hand, our results of the decrease of protein synthesis in the pulmonary cells with age are different from the investigation in rat lung by Goldspink and Merry [14]. They reported that there was little or no postnatal decline in the fractional rates of protein synthesis from weaning to old age in the rat lungs. The difference may be due to the species difference.

The lung is a metabolically active organ. The type II epithelial cells can synthesize and secrete pulmonary surfactant [2]. The pulmonary interstitial fibroblast can produce elastin which is an elastic extracellular matrix protein and plays an important structural and functional role in the lung tissue $[3,6,27]$. Our data in the present study showed that the protein syntheses were higher in both the type II epithelial cells and interstitial cells than those in the other type I epithelial cells and endothelial cells at the same age groups. These results suggest that the reason why the protein syntheses in these two types of cells, type II epithelial cells and interstitial cells, were higher than the other two types of cells, type I epithelial cells and endothelial cells, may be due to the production and secretion of either pulmonary surfactant or extracellular matrix.

In summary, the present study is the first to examine the changes of protein synthesis in respective pulmonary cell types of aging mouse lung from prenatal stage to postnatal senescent stages. Our results revealed that: (1) The protein syntheses in type I epithelial cells, type II epithelial cells, interstitial cells and endothelial cells in mouse lung underwent age-related changes with increasing 
age. (2) The protein synthesis of type I epithelial cells reached its maximum on postnatal day 1 , increased again at 1 week after birth, then decreased progressively to 22 months after birth with aging. (3) The protein syntheses of type II epithelial cells, interstitial cells and endothelial cells reached the highest level on fetal day 16 , and declined progressively with age, then increased again at 1 week after birth, diminished gradually from 2 weeks to senility (22 months after birth). (4) In each aging group, the cytoplasmic protein synthesis was always higher than the nucleoprotein synthesis. (5) In each aging group, the protein syntheses in type II epithelial cells and interstitial cells were higher than the other two types of cells suggesting the productions of surfactant and extracellular matrix.

\section{Acknowledgments}

This study was supported in part by a Grant-in-Aids for Scientific Research from the Ministry of Education, Science and Culture of Japan (No. 02454564) given to the last author (T.N.). The first author (L.S.) was an awardee for a Yoneyama foreign student scholarship from Japan Rotary Club during her study as a graduate student at Shinshu University.

\section{References}

1. Adenuga, G. A., Mazaev, A. G. and Olowookere, J. O.: The peculiarities of protein and RNA syntheses in the hepatic mitochondria of young and old animals: Studies without the use of an antibiotic. Exp. Gerontol. 23; 35-41, 1988.

2. Askin, F. B. and Kuhn, C.: The cellular origin of pulmonary surfactant. Lab. Invest. 25; 260-268, 1971.

3. Berk, J. L., Franzblau, C. and Goldstein R. H.: Recombinant interleukin- $1 \beta$ inhibits elastin formation by a neonatal rat lung fibroblast subtype. J. Biol. Chem. 266; 3192-3197, 1991.

4. Burri, P. H.: The postnatal growth of the rat lung. III. Morphology. Anat. Rec. 180; 77-98, 1974.

5. Bustany, P., Trenque, T., Crambes, O. and Moulin, M.: Restoration of brain protein synthesis in mature and aged rats by a DA agonist, piribedil. Fundam. Clin. Pharmacol. 9; 458-468, 1995.

6. Campagnone, R., Regan, J., Rich, C. B., Miller, M., Keene, D. R., Sakai, L. and Foster, J. A.: Methods in laboratory investigation, pulmonary fibroblasts: A model system for studying elastin synthesis. Lab. Invest. 56; 224-230, 1987.

7. D,Costa, A.P., Xu, X., Ingram, R. L. and Sonntag, W. E.: Insulin-like growth factor-1 stimulation of protein synthesis is attenuated in cerebral cortex of aging rats. Neuroscience 65; 805-813, 1995.

8. Gao, F.: Study on the macromolecular synthesis in aging mouse seminiferous tubules by light and electron microscopic radioautography. Cell. Mol. Biol. 39; 659-672, 1993.

9. Gao, F., Ma, H., Sun, L., Jin, C. and Nagata, T.: Electron microscopic radioautographic study on the nucleic acids and protein syntheses in the aging mouse testis. Med. Electron Microsc. 27; 360-362, 1994.

10. Gao, F., Sun, L., Chen, S., Jin, C., Ma, H. and Nagata, T.: Radioautographic study on the macromolecular synthesis of Leydig cells in the testis of aging mouse. In "Radioautography in Medicine", ed. by T. Nagata, Shinshu University Press, Matsumoto, 1994, pp. 220-224.
11. Gao, F., Chen, S., Sun, L., Kang, W., Wang, Z. and Nagata, T.: Radioautographic study on the macromolecular synthesis of Leydig cells in aging mice testis. Cell. Mol. Biol. 41; 145-150, 1995.

12. Goldspink, D. F.: Pre- and post-natal growth and protein turnover in the lung of the rat. Biochem. J. 242; 275-279, 1987.

13. Goldspink, D. F. and Kelly, F. J.: Protein turnover and growth in the whole body, liver and kidney of the rat from the foetus to senility. Biochem. J. 217; 507-516, 1984.

14. Goldspink, D.F. and Merry, B. J.: Changes in protein turnover and growth of the rat lung in response to ageing and longterm dietary restriction. Mech. Ageing Dev. 42; 253-262, 1988.

15. Goldspink, D. F., Lewis, S. E. M. and Kelly, F. J.: Protein synthesis during the developmental growth of the small and large intestine of the rat. Biochem. J. 217; 527-534, 1984.

16. Gozes, I., Cronin, B. L. and Moskowitz, M. A.: Protein synthesis in rat brain microvessels decreases with aging. $J$. Neurochem. 36; 1311-1315, 1981.

17. Kimball, S. R., Vary, T. C. and Jefferson, L. S.: Age-dependent decrease in the amount of eukaryotic initiation factor 2 in various rat tissues. Biochem. J. 286; 263-268, 1992.

18. Layman, D. K., Ricca, G. A. and Richardson, A.: The effect of age on protein synthesis and ribosome aggregation to messenger RNA in rat liver. Arch. Biochem. Biophys. 173; 246-254, 1976.

19. Lewis, S. E. M., Kelly, F. J. and Goldspink, D. F.: Pre- and post-natal growth and protein turnover in smooth muscle, heart and slow- and fast-twitch skeletal muscles of the rat. Biochem. J. 217; 517-526, 1984.

20. Ma, H., Gao, F. and Nagata, T.: Study on protein synthesis in the livers of aging mice by means of electron microscopic radioautography. J. Clin. Electron Microsc. 25; 5-6, 1992.

21. Ma, H., Gao, F., Olea, M. T. and Nagata, T.: Protein synthesis in the livers of aging mice studied by electron microscopic radioautography. Cell. Mol. Biol. 37; 607-615, 1991.

22. Ma, H., Chen, S., Gao, F. and Nagata, T.: DNA, RNA and protein synthesis in the livers of aging mice studied by electron microscopic radioautography. In "Radioautography in Medicine", ed. by T. Nagata, Shinshu University Press, Matsumoto, 1994, pp. 122-126.

23. Ma, H., Gao, F., Sun, L., Jin, C. and Nagata, T.: Electron microscopic radioautographic study on the syntheses of DNA, RNA, and protein in the livers of aging mice. Med. Electron Microsc. 27; 352-354, 1994.

24. Marshak, T. L., Dungenova, R. E. and Brodskii, V. Y.: Protein synthesis in the liver and cerebellum of rats growing at different rates of intensity. Ontogenez 26; 430-436, 1995.

25. Mays, P. K., McAnulty, R. J. and Laurent, G. J.: Age-related changes in lung collagen metabolism. Am. Rev. Respir. Dis. 140; 410-416, 1989.

26. Mays, P. K., McAnulty, R. J. and Laurent, G. J.: Age-related changes in rates of protein synthesis and degradation in rat tissues. Mech. Ageing Dev. 59; 229-241, 1991.

27. McGowan, S. E., Harvey, C. S. and Jackson, S. K.: Retinoids, retinoic acid receptors, and cytoplasmic retinoid binding proteins in perinatal rat lung fibroblasts. Am. J. Physiol. (Lung Cell. Mol. Physiol. 13) 269; L463-L472, 1995.

28. Nagata, T.: Simple method for mass production of radioautographs. Saibo (The Cell) 14; 40-50, 1982.

29. Nagata, T.: Radiolabeling of soluble and insoluble compounds as demonstrated by light and electron microscopy. In "Recent Advances in Cellular and Molecular Biology”, vol. 6, ed. by R. J. Wegmann and M. A. Wegmann, Peeters Press, Leuven, 1992, pp. 9-21.

30. Nagata, T.: Quantitative analysis of histochemical reactions: Image analysis of light and electron microscopic radioautogram. Acta Histochem. Cytochem. 26; 281-291, 1993. 
31. Nagata, T.: Quantitative light and electron microscopic radioautographic studies on macromolecular synthesis in several organs of prenatal and postnatal aging mice. Chin. J. Histochem. Cytochem. 2; 106-108, 1993.

32. Nagata, T.: Application of electron microscopic radioautography to clinical electron microscopy. Med. Electron. Microsc. 27; 191-212, 1994.

33. Nagata, T.: Light and electron microscopic radioautographic studies on macromolecular synthesis in digestive organs of aging mice. Cell. Mol. Biol. 41; 21-38, 1995.

34. Nagata, T. and Usuda, N.: Electron microscopic radioautography of protein synthesis in pancreatic cells of aging mice. Acta Histochem. Cytochem. 26; 481-481, 1993.

35. Rattan, S. I. S.: Synthesis, modifications, and turnover of proteins during aging. Exp. Gerontol. 31; 33-47, 1996.

36. Riis, B., Rattan, S. I. S., Derventzi, A. and Clark, B. F. C.: Reduced levels of ADP-ribosylatable elongation factor-2 in aged and SV40-transformed human cell cultures. FEBS Lett. 266; 45-47, 1990.

37. Shahbazian, F. M., Jacobs, M. and Lajtha, A.: Rates of protein synthesis in brain and other organs. Int. J. Dev. Neurosci. 5; 39-42, 1987.

38. Sun, L.: Age-related changes of RNA synthesis in the lungs of aging mice by light and electron microscopic radioautography.
Cell. Mol. Biol. 41; 1061-1072, 1995.

39. Sun, L., Gao, F. and Nagata, T.: Study on the DNA synthesis of pulmonary cells in aging mice by light microscopic radioautography. Cell. Mol. Biol. 41; 851-859, 1995.

40. Sun, L., Gao, F., Duan, H. and Nagata, T.: Light microscopic radioautography of DNA synthesis in pulmonary cells in aging mouse. In "Radioautography in Medicine", ed. by T. Nagata, Shinshu University Press, Matsumoto, 1994, pp. 201-205.

41. Sun, L., Gao, F., Jin, C., Duan, H. and Nagata, T.: An electron microscopic radioautographic study on the DNA synthesis of pulmonary tissue cells in aging mice. Med. Electron Microsc. 28; 130-132, 1995.

42. Toriyama, K.: Study on the aging changes of DNA and protein synthesis of bipolar and photoreceptor cells of mouse retina by light and electron microscopic radioautography. Cell. Mol. Biol. 41; 593-601, 1995.

43. Van den Bosch de Aguilar, P. and Vanneste, J.: Ageing of the spinal ganglion neurons in the rat: A radioautographic study following injection of $\left[{ }^{3} \mathrm{H}\right]$ lysine. Neurosci. Lett. 18; 225-230, 1980.

44. Yamada, A. T.: Timely and topologically defined protein synthesis in the peri-implanting mouse endometrium revealed by light and electron microscopic radioautography. Cell. Mol. Biol. 39; 1-12, 1993. 